\title{
Age related cognitive decline: a clinical entity? A longitudinal study of cerebral blood flow and memory performance
}

\author{
P Celsis, A Agniel, D Cardebat, J F Démonet, P J Ousset, M Puel
}

\begin{abstract}
Objectives-To evaluate the changes in regional cerebral blood flow (rCBF) and memory performance in patients with age related cognitive decline (ARCD) who did and did not become demented during a follow up period.

Methods-Twenty four patients with ARCD were recruited from an outpatient memory clinic, of whom 18 were followed up over a mean period of two years. Eighteen patients with mild to moderate probable Alzheimer's disease and 18 aged normal controls were followed up over a mean period of three years. Memory performance and rCBF were evaluated quantitatively at inclusion and during follow up, using single photon emission computed tomography with xenon-133 injection and three subtests of the Wechsler memory scale (logical memory, paired associated learning, and digit span).

Results-Patients with ARCD showed decreased rCBF and memory performance at initial evaluation compared with controls. Five of them became demented during the follow up period, with further decline in memory and rCBF. At inclusion, the only feature that distinguished these five patients as a group from the remainder was a pronounced temporoparietal asymmetry. The 13 patients with ARCD who did not become demented still exhibited impaired memory and rCBF at follow up, but without any further decline and no increase in flow asymmetry.

Conclusions-Apart from patients in the preclinical phase of Alzheimer's disease, the ARCD category includes nondemented patients who have brain dysfunction that may represent a distinct clinical entity.
\end{abstract}

(F Neurol Neurosurg Psychiatry 1997;62:601-608)

Keywords: age related cognitive decline; cerebral blood flow; memory; Alzheimer's disease; longitudinal study

Older people often complain of memory loss and a mild but objective cognitive impairment is commonly found in elderly subjects. ${ }^{1-3}$ The natural history of these age related cognitive deficits is not well known and different diagnostic categories have been proposed. These categories, whatever their name and the clini- cal criteria they are built on, include aged persons who are not demented and the mild memory or cognitive decline they show cannot be accounted for by any recognised medical or psychiatric condition. Given the importance of the very early detection of a dementing process, ${ }^{4}$ we need to improve our knowledge of the relation between the age related cognitive decline (ARCD), as termed in the DSMIV, ${ }^{5}$ and normal aging on the one hand, and dementia such as Alzheimer's disease on the other. This is a particularly interesting issue as recent longitudinal studies indicate that the preclinical stage of Alzheimer's disease is characterised by changes in cognitive abilities that may predict the subsequent development of overt dementia. ${ }^{6-8}$

Neuroimaging techniques have added valuable information to the clinical evaluation of Alzheimer's disease. Consistent patterns of regional cerebral blood flow (rCBF) or metabolic defects have been reported in PET or single photon emission computed tomography (SPECT) studies, although the sensitivity and specificity of the techniques in the early stage of the disease have not been clearly established..$^{9-12}$ Quantitative MRI studies have also documented a decrease in volume of the medial temporal lobe structures in Alzheimer's disease,,$^{1314}$ and two studies in aged normal subjects have reported a positive relation between the performance on memory tests and the volume of the hippocampal formation. ${ }^{15}$ Only recently has imaging technology been applied to the study of ARCD and variants. ${ }^{17-19}$ Although most authors agree that a follow up of the subjects will be necessary to clarify the relation between the anatomical or functional changes in the brain and ARCD, only cross sectional data have been reported so far.

In the present longitudinal study, we measured the rCBF and memory performance of patients with ARCD and compared their initial and follow up values with those of age matched controls and patients with probable Alzheimer's disease, distinguishing the patients with ARCD who became demented from those who did not.

\section{Methods}

SUBJECTS

The 24 patients in the ARCD group were selected from outpatients with memory complaints who were referred to the memory clinic of the Department of Neurology, University Hospital, Toulouse, over one year. They were 
examined by a neurologist, a psychiatrist, and a neuropsychologist trained in the evaluation of aged persons and the diagnosis of dementia. All of them were administered a physical and neurological examination, the short French version $^{20}$ of the McNair and Kahn cognitive difficulties scale (CDS), ${ }^{21}$ the mini mental state examination (MMSE), ${ }^{22}$ subtests of the Wechsler memory scale (WMS), ${ }^{23}$ and the Hamilton rating scale for depression. ${ }^{24}$ Additional neuropsychological evaluations were performed each time a decline in the performance of other cognitive abilities, mainly language, reasoning, or planning of a complex action, was suspected. When indicated by the clinical evaluation, CT, MRI, and appropriate laboratory tests were also performed. The 24 patients in the ARCD group (1) had a decline in memory or another cognitive function in comparison with the standardised performance of an age and education matched subject (when education norms were lacking, a $10 \%-12 \%$ decline compared with the expected performance was considered as normal for those with eight years of education or less); (2) scored over 24 on the MMSE and over 36 on the CDS; (3) scored less than nine on the Hamilton depression scale; and (4) were free of any neurological, psychiatric, or medical disorder and of drug use that could induce cognitive deterioration, and were independent in all activities of daily living. These patients met the criteria defined by the Working Party of the International Psychogeriatric Association $^{25}$ and could be included in the new diagnostic category of age related cognitive decline of the DSM IV. ${ }^{5}$ The focus of clinical attention was a mild but objective memory or cognitive decline that could not be attributed to a specific mental or neurological disorder. None of the patients was demented at initial evaluation according to the DSM III-R ${ }^{26}$ criteria for dementia. Some of them met the criteria for age associated memory impairment (AAMI), ${ }^{27}$ the modified criteria for AAMI, ${ }^{28}$ or the International Classification of Diseases (ICD-10) criteria for mild cognitive impairment. ${ }^{29}$ As none of these categories fitted the whole group and as none had a clear superiority, we considered the new ARCD category as the most appropriate.

For each of the patients in the ARCD group, we calculated an auditory verbal memory score (AVMS) by adding up the scores on the logical memory (immediate recall) and paired associate learning (easy and hard word pairs, immediate recall) subtests of the WMS. ${ }^{23}$ The digit span (DS, forward and backward) was also administered. Regional cerebral blood flow (rCBF) was measured by SPECT according to the procedure described below. Eighteen of the 24 patients with ARCD were followed up and had the memory testing repeated using the same tests. The rCBF measurement was also repeated. We telephoned the family physicians of the six subjects who were lost to follow up. Their answers allowed us to consider that, three years after inclusion, none of the patients had become demented. Despite our efforts, we failed to follow up each of our patients on the planned regular basis of one examination a year during three years. When several examinations were available, the last one was used for the study. Thus eight patients were followed up after one year, seven after two years, and three after three years.

The 18 patients of the probable Alzheimer's disease group were selected from among patients followed up in the Department of Neurology, University Hospital, Toulouse, and who met the NINCDS-ADRDA criteria for probable Alzheimer's disease. In addition, they had to score between 10 and 23 on MMSE at initial evaluation, and to have been followed up for at least one year with a second rCBF examination. The memory scores (AVMS and DS) at initial examination were also available for the patients with probable Alzheimer's disease.

Eighteen age matched normal volunteers were included as controls. These volunteers were subjects of an ongoing longitudinal study on $\mathrm{rCBF}$ in normal elderly persons. They had a normal neurological examination, no history of cerebral vascular or psychiatric disease, and normal CT. They did not receive the MMSE but their memory evaluation included the three subtests of the WMS used for calculating the AVMS and DS. They were followed up for at least one year and had at least two memory and rCBF measurements.

Written informed consent was obtained from the normal volunteers and from the subjects of the ARCD group. The local ethics committee approved the study.

SPECT IMAGING OF RCBF

Regional cerebral blood flow was measured using SPECT (Tomomatic 64, Medimatic, Copenhagen, Denmark) and intravenous injection of xenon-133 (2200 MBq). Data were collected from three transverse slices simultaneously, each $2 \mathrm{~cm}$ thick, parallel, and centred at 1,5 , and $9 \mathrm{~cm}$ above the orbitomeatal plane. The in plane resolution was $1 \cdot 7$ $\mathrm{cm}$.

The subject's head was positioned at the appropriate level and in the appropriate direction according to graduated external markers. Marks were also drawn on the skin of the subject's face, and photographs of the head and of the marks were used for correct repositioning of the head at subsequent SPECT. During the four minute data collection, the subjects were lying with their eyes closed in a quiet dimly lit room. Absolute rCBF values were then calculated from the reconstructed images according to a method described previously. ${ }^{30}$ The rCBF data were then transferred to a MacIntosh microcomputer for image analysis.

For the present study, we only analysed the images of the midslice (orbitomeatal plane+5) because this encompassed a large part of the associative cortices commonly reported to show the earliest and the most demonstrative defects in Alzheimer's disease. Mean flow in the slice $(\mathrm{ml} / 100 \mathrm{~g} / \mathrm{min})$ was first calculated by averaging all the pixels of the slice. Then, according to the visual analysis of the image and to data of an anatomical stereotaxis atlas, ${ }^{31}$ 
Table 1 Characteristics at initial screening of controls, patients with age related cognitive decline (ARCD), and patients with probable Alzheimer's disease (AD)

\begin{tabular}{|c|c|c|c|}
\hline & Controls & $A R C D$ & Probable $A D$ \\
\hline $\begin{array}{l}\text { Subjects (n) } \\
\text { Women/men } \\
\text { Age (y) } \\
\text { Education (y) } \\
\text { MMSE } \\
\text { AVMS } \\
\text { DS } \\
\text { Subjects followed up (n) } \\
\text { Duration of follow up (y) }\end{array}$ & $\begin{array}{l}18 \\
10 / 8 \\
65 \cdot 3(6 \cdot 0) \\
12 \cdot 1(4 \cdot 8) \\
\frac{32}{32} \cdot 5(4 \cdot 5) \\
10 \cdot 8(1 \cdot 8) \\
18 \\
3 \cdot 2(1 \cdot 2)\end{array}$ & $\begin{array}{l}24 \\
11 / 13 \\
62 \cdot 2(8 \cdot 8) \\
10 \cdot 0(2 \cdot 9) \\
27 \cdot 5(1 \cdot 9) \\
23 \cdot 7(6 \cdot 7) \\
9 \cdot 5(1 \cdot 7) \\
18 .(1 \cdot 0)\end{array}$ & $\begin{array}{l}18 \\
7 / 11 \\
64 \cdot 1(6 \cdot 5) \\
9 \cdot 2(2 \cdot 0) \\
14 \cdot 5(7 \cdot 4) \\
9 \cdot 6(5 \cdot 9) \\
7 \cdot 0(1 \cdot 9) \\
18 \\
3 \cdot 0(1 \cdot 5)\end{array}$ \\
\hline
\end{tabular}

Values with parentheses are means (SD)

MMSE = mini mental state examination; AVMS = auditory verbal memory score; $D S$ = digit span.

we drew one large region of interest (ROI) in the parietal and temporal cortices of each hemisphere. These two ROIs corresponded to the posterior regions of pronounced hypoperfusion in patients with Alzheimer's disease, and their delineation was based on the experience of one of us (PC) in the analysis of the rCBF images of more than 200 patients with probable Alzheimer's disease. The delineation was made blind to the diagnosis, but obviously, for most of the patients with probable Alzheimer's disease, little doubt existed as to the diagnostic category after their rCBF image had been studied. We then calculated a parietotemporal flow value in $\mathrm{ml} / 100 \mathrm{~g} / \mathrm{min}$ by averaging the pixels of the right and left ROIs. Because asymmetries between homologous association cortices have been reported in the early stages of probable Alzheimer's disease, ${ }^{10}$ we also calculated the difference between the left and right parietotemporal flows, which is reported here as the parietotemporal asymmetry (unsigned). The absolute value rather than the signed value of the difference was used to allow for an averaged estimate of the magnitude of the asymmetry. To reduce the influence of between patient variability, we calculated an index of relative, normalised perfusion of these posterior regions, the parietotemporal: mean flow ratio.

\section{STATISTICAL ANALYSIS}

The data were analysed using the StatView IV and SuperANOVA software (Abacus Concepts Inc, Berkeley, CA, USA). A multivariate analysis of covariance (MANCOVA) was applied to the memory scores and to the set of rCBF variables, with age and education as covariates for the initial values, and age, education, and duration of follow up as covariates for follow up values. When significant, the overall multivariate test (Wilk's lambda test) indicates that the groups are significantly different on the set of memory scores or flow variables. Univariate

Table 2 Initial cerebral blood flow in controls, patients with age related cognitive decline $(A R C D)$, and patients with probable Alzheimer's disease (AD)

\begin{tabular}{|c|c|c|c|}
\hline & Controls & $A R C D$ & Probable $A D$ \\
\hline $\begin{array}{l}\text { Mean flow } \\
\text { Parietotemporal flow } \downarrow \\
\text { Parietotemporal asymmetry } \\
\text { Parietotemporal/mean } ₫\end{array}$ & $\begin{array}{l}57(8) \\
52(7) \\
2 \cdot 2(1 \cdot 9) \\
0 \cdot 91(0 \cdot 06)\end{array}$ & $\begin{array}{l}52(8) \uparrow \\
46(7)|| \\
2 \cdot 9(2 \cdot 4) \\
0 \cdot 89(0 \cdot 05) \star \star\end{array}$ & $\begin{array}{l}47(9) \\
35(9) \\
3.9(1 \cdot 8) \\
0.75(0 \cdot 09)\end{array}$ \\
\hline
\end{tabular}

Values are means (SD).

Mean flow, parietotemporal flow, and asymmetry are in $\mathrm{ml} / 100 \mathrm{~g} / \mathrm{min}$

${ }^{\star}$ Group effect: $F_{57}^{2}=7 \cdot 3, P<0.01$; tgroup effect: $F_{57}^{2}=21.9, P<0.001$; †group effect: $\mathrm{F}_{57}^{2}=3 \cdot 1$, NS; Igroup effect: $\mathrm{F}_{57}^{2}=31, \mathrm{P}<0.001$; Idiffers from controls $(\mathrm{P}<0.05)$; | differs from controls $(\mathrm{P}<0.02)$ and from probable $\mathrm{AD}(\mathrm{P}<0.001)$; ${ }^{\star \star}$ differs from probable $\mathrm{AD}$ $(\mathbf{P}<0.001)$.
ANCOVA by group was then applied to each variable of the sets, followed, when the omnibus $F$ value was significant, by post hoc comparisons using Fisher's protected least significant difference (PLSD). Although protected against multiple comparison effects, the PLSD is less conservative than Scheffe's $S$ test, and thus may lead to a greater number of significant findings that may be due to chance. However, given the small size of our samples, we chose to favour the power of the test.

\section{Results}

CLINICAL CHARACTERISTICS

Age, sex, and education did not differ between groups (table 1). Controls were slightly better educated than the patients with ARCD and those with probable Alzheimer's disease. The duration of the follow up was shorter for the ARCD group (two years) compared with controls and patients with probable Alzheimer's disease (three years). None of these covariates affected the differences in MMSE, AVMS, DS, and $\mathrm{rCBF}$ between groups. As a result of the selection, the MMSE of the patients with ARCD was much higher than that of patients with probable Alzheimer's disease. In the ARCD group, the memory performance was about $25 \%$ lower than in controls, whereas the memory impairment of the those with ARCD was clearly less than that of patients with probable Alzheimer's disease.

\section{REGIONAL CBF AT INITIAL EVALUATION}

We found a significant group effect for the initial measures of rCBF (Wilk's Lambda $F^{8}{ }_{108}=$ $10, P<0.001)$. Mean flow of the subjects with ARCD was between the mean flow of controls and the mean flow of patients with probable Alzheimer's disease (table 2). Mean flow was thus significantly lower in patients with ARCD than controls, and higher compared with patients with probable Alzheimer's disease $(P=0.06)$. Flow in the parietotemporal regions was also significantly lower in patients with ARCD than in controls, but much higher than in patients with probable Alzheimer's disease (table 2). The parietotemporal asymmetry seemed more pronounced in the ARCD group, but not significantly, whereas it was clearly larger in patients with probable Alzheimer's disease. The ratio of parietotemporal:mean flow did not differ between ARCD and controls but it was significantly higher in patients with ARCD than in patients with probable Alzheimer's disease. These results indicated that in the patients with ARCD as a whole, hypoperfusion did not predominate in the temporoparietal regions, as was the case for the patients with probable Alzheimer's disease, but flows in these regions were slightly more asymmetric than in controls.

CLINICAL DISTINCTION BETWEEN THE PATIENTS WITH ARCD WHO DID AND DID NOT BECOME DEMENTED

The follow up clinical evaluations of our patients with ARCD allowed us to distinguish five patients who presented with clinical evi- 
Table 3 Initial and follow up mini mental state evaluation (MMSE), auditory verbal memory score (AVMS), and digit span (DS) in controls and patients with age related cognitive decline (ARCD) who did and did not become demented

\begin{tabular}{|c|c|c|c|}
\hline & \multirow[b]{2}{*}{$\begin{array}{l}\text { Controls } \\
(n=18)\end{array}$} & \multicolumn{2}{|l|}{$A R C D$} \\
\hline & & $\begin{array}{l}\text { Non-demented } \\
(n=13)\end{array}$ & $\begin{array}{l}\text { Demented } \\
(n=5)\end{array}$ \\
\hline MMSE (initial) & - & $27 \cdot 7(2 \cdot 0)$ & $26 \cdot 5(1 \cdot 3)$ \\
\hline MMSE (follow up) & - & $28 \cdot 2(1 \cdot 8)$ & $21 \cdot 5(1 \cdot 7)$ \\
\hline AVMS (initial) & $32 \cdot 5(4 \cdot 5)$ & $26 \cdot 5(7 \cdot 1)$ & $19 \cdot 8(3 \cdot 7)$ \\
\hline AVMS (follow up) & $35 \cdot 5(1 \cdot 8)$ & $29 \cdot 8(4 \cdot 8)$ & $12 \cdot 2(4 \cdot 1)$ \\
\hline Rate of decline in AVMS ${ }^{\star}$ & $0.5(0.9)$ & $1 \cdot 3(4 \cdot 8)$ & $-3 \cdot 0(2 \cdot 7)$ \\
\hline DS (initial) & $10 \cdot 8(1 \cdot 8)$ & $9 \cdot 2(1 \cdot 3)$ & $9 \cdot 6(2 \cdot 6)$ \\
\hline DS (follow up) & $12.6(1.5)$ & $9.5(1.6)$ & $8 \cdot 7(2 \cdot 1)$ \\
\hline Rate of decline in DSt & $0.2(0.4)$ & $0.3(0.8)$ & $-0.9(0.6) \ddagger$ \\
\hline
\end{tabular}

Values are means $(\mathrm{SD})$.

Rate of decline = (initial - follow up)/duration of follow up (y)

${ }^{\star}$ Group effect: $F_{33}^{2}=1.4, N S$; tgroup effect: $F_{33}^{2}=3.9, P<0.05$; $\neq$ differs from controls $(\mathrm{P}<0.05)$ and from ARCD-non-demented $(\mathrm{P}<0.02)$.

dence of dementia. At the follow up examination, these five patients met the NINCDSADRDA criteria for probable Alzheimer's disease, with obvious deficits in several of the higher brain functions. Table 3 gives the initial and follow up MMSE, AVMS, and DS values, as well as the rate of decline of these scores, for the five patients with ARCD who became demented and for the 13 who did not. The MANCOVA showed a global group effect on the memory scores, both at initial (Wilk's Lambda $\left.F_{64}^{4}=5.4, P<0.001\right)$ and follow up (Wilk's Lambda $F_{64}^{4}=12.9, P<0.001$ ) examinations, but the global group effect on the rate of decline in memory scores was not significant (Wilk's lambda $F_{64}^{4}=2 \cdot 14$ ). Univariate tests showed, however, that the rate of decline of the DS was significantly higher in the ARCD demented group than in the ARCD non-demented and control groups, which did not decline (positive values). Although the difference did not reach significance, the rate of decline of the AVMS was clearly more pronounced in the ARCD demented patients than in the ARCD nondemented patients and control subjects (table 3). To summarise, at follow up, there was a clear decline in DS and AVMS in the ARCD demented group which was not seen in the non-demented group. Moreover, the rate of decline in MMSE of the ARCD demented group was identical with that of the patients with probable Alzheimer's disease ( -2.3 (SD $1 \cdot 6) \mathrm{v}-2 \cdot 3(\mathrm{SD} 2 \cdot 0)$ respectively). Although

Table 4 Follow up cerebral blood flow in controls, patients with age related cognitive decline (ARCD) who did and did not become demented, and patients with probable Alzheimer's disease (AD)

\begin{tabular}{|c|c|c|c|c|}
\hline & \multirow[b]{2}{*}{ Controls } & \multicolumn{2}{|l|}{$A R C D$} & \multirow[b]{2}{*}{ Probable $A D$} \\
\hline & & Non-demented & Demented & \\
\hline $\begin{array}{l}\text { Mean flow } \\
\text { Rate of decline } \\
\text { Parietotemporal flow } \\
\text { Rate of decline } \\
\text { Parietotemporal asymmetry } \\
\text { Parietotemporal/mean } \\
\text { Rate of decline }\end{array}$ & $\begin{array}{l}56(9) \\
-0.3(1 \cdot 9) \\
50(7) \\
-0.5(1.9) \\
1.7(1 \cdot 6) \\
0.90(0 \cdot 06) \\
-0.3(1 \cdot 4)\end{array}$ & $\begin{array}{l}52(8)^{\star} \\
0 \cdot 7(4 \cdot 4) \\
45(6) \ddagger \\
-0 \cdot 3(4 \cdot 2) \\
2 \cdot 2(1 \cdot 6) \\
0 \cdot 87(0 \cdot 07)|| \\
-1 \cdot 6(3 \cdot 0)\end{array}$ & $\begin{array}{l}51(15) \dagger \\
-0 \cdot 8(8 \cdot 8) \\
42(12) \S \\
-2 \cdot 0(4 \cdot 9) \\
4 \cdot 8(4 \cdot 5) 9 \\
0 \cdot 82(0 \cdot 05) \\
-2 \cdot 3(3 \cdot 6)\end{array}$ & $\begin{array}{l}43(6) \\
-1 \cdot 3(4 \cdot 6) \\
31(6) \\
-1 \cdot 3(4 \cdot 2) \\
3 \cdot 4(1 \cdot 7) \\
0 \cdot 73(0 \cdot 09) \\
-0 \cdot 8(4 \cdot 0)\end{array}$ \\
\hline
\end{tabular}

Values are means $(\mathrm{SD})$ Mean flow, parietotemporal flow, and asymmetry are in $\mathrm{ml} / 100 \mathrm{~g} / \mathrm{min}$. Rate of decline for mean
flow and parietotemporal flow are in $\mathrm{ml} / 100 \mathrm{~g} / \mathrm{min}$ per year. Rate of decline in parietoflow and parietotemporal flow

temporal $/$ mean is in \% per year.
${ }^{\star D}$ Differs from probable AD $(P<0.01)$; $\dagger$ differs from probable AD $(P<0.05)$; $\ddagger$ differs from *Differs from probable AD $(P<0.01)$; †differs from probable $\mathrm{AD}(\mathrm{P}<0.05)$; †differs from
controls $(\mathrm{P}<0.05)$ and from probable $\mathrm{AD}(\mathrm{P}<0.001)$; 〔differs from controls $(\mathrm{P}<0.01)$ and from probable $\mathrm{AD}(\mathrm{P}<0.01)$; Idiffers from controls $(\mathrm{P}<0.01)$ and from $\mathrm{ARCD}-$ nondemented $(P<0.05)$; | | differs from probable $\mathrm{AD}(\mathbf{P}<0.001)$; ${ }^{\star}$ differs from controls $(\mathrm{P}<0.05)$ and from probable $\mathrm{AD}(\mathrm{P}<0.01)$. there was no further decline in the memory performance of the ARCD non-demented group, their AVMS and DS remained lower than those of the controls at follow up.

REGIONAL CBF AT FOLLOW UP IN THE DEMENTED AND NON-DEMENTED PATIENTS WITH ARCD

Table 4 summarises the follow up rCBF characteristics of the demented and non-demented patients with ARCD, in comparison with the flow values of controls and patients with probable Alzheimer's disease. There was a significant group effect on the set of the flow variables (Wilk's lambda $F^{12}{ }_{124}=8 \cdot 3, \quad \mathrm{P}<$ 0.001 ), but not on the rates of decline (Wilk's lambda $\left.F_{117}^{9}=0 \cdot 7, \mathrm{NS}\right)$. However, the rates of decline seemed higher in the ARCD demented group than in the ARCD nondemented group and controls. In addition, the rCBF values of the demented group showed that the decrease mostly affected the parietotemporal regions, as indicated by a significantly lower parietotemporal:mean flow ratio, but predominantly on one side, as indicated by an increased parietotemporal asymmetry. In the ARCD demented group, absolute flows and their ratio remained significantly higher than those of the initially constituted probable Alzheimer's disease group, but were lower than those of the ARCD non-demented group. The non-demented patients still exhibited lower flows than controls, the decrease being significant in the temporoparietal regions. Thus the flow pattern across groups appeared as a progressive and ordered decrease from controls to ARCD nondemented patients, then to ARCD demented patients, and finally to patients with probable Alzheimer's disease, with a peak in asymmetry for the ARCD demented group.

INITIAL RCBF IN THE DEMENTED AND NON-DEMENTED PATIENTS WITH ARCD As we found five patients with ARCD who became demented, we wanted to verify whether these were responsible for the flow decrease at initial evaluation in the whole ARCD group, and whether they presented with more pronounced hypoperfusion or asymmetry in their posterior cortical regions, two findings that may help predict the future development of overt dementia. We therefore recalculated the initial flow data separately for the demented and non-demented patients with ARCD (table 5). The initial rCBF values

Table 5 Initial cerebral blood flow in patients with age related cognitive decline (ARCD) who did and did not become demented

\begin{tabular}{lll}
\hline & \multicolumn{2}{l}{$A R C D$} \\
\cline { 2 - 3 } & Non-demented & Demented \\
\hline Mean flow & $51(9)$ & $55(5)$ \\
Parietotemporal flow & $46(9)^{\star}$ & $48(5)$ \\
Parietotemporal asymmetry & $2 \cdot 0(1 \cdot 8)$ & $4.4(3.0) \dagger$ \\
Parietotemporal/mean & $0.89(0.04)$ & $0.87(0.07)$ \\
\hline
\end{tabular}

Values are means (SD).

Mean flow, parietotemporal flow, and asymmetry are in $\mathrm{ml} / 100 \mathrm{~g} / \mathrm{min}$.

${ }^{\star}$ Differs from controls $(P<0.05$, see value table 2$)$; $\ddagger$ differs from ARCD (non-demented) $\left(\mathrm{F}_{16}^{2}=4.5, \mathrm{P}<0.05\right)$. 
of the demented patients were lower than those of controls but none of the decreases reached significance. Strikingly, the decrease was even more pronounced in the nondemented group, in which it reached significance for the parietotemporal flow. These initial rCBF values allowed us to calculate the decline with time (difference between the two consecutive rCBF measurements) for the demented and non-demented patients with ARCD. The decline in the temporoparietal region tended to be more pronounced in the ARCD demented group $(-6 \mathrm{ml} / 100 \mathrm{~g} / \mathrm{min})$ than in the ARCD non-demented group $(-1 \mathrm{ml} / 100 \mathrm{~g} / \mathrm{min}$ ) but the difference was non-significant $(P=0 \cdot 13)$. The two groups did not differ with regard to the set of flow variables (Wilk's lambda $F_{13}^{4}=1 \cdot 6, \mathrm{NS}$ ), but the five patients who later developed dementia already showed a pronounced asymmetry not found in the patients who did not become demented (table 5). In four cases out of five, the hypoperfusion predominated on the right side. However, the individual predictive value of this measure was weak, as only three patients of five showed an initial asymmetry that exceeded the mean asymmetry of controls by more than $1 \mathrm{SD}$.

\section{Discussion}

Whether ARCD and variants are part of normal aging, are prodromal to dementia, or represent a distinct clinical and pathological entity is crucial for the early diagnosis of a dementing process. Finding biological markers that could help distinguish between the corresponding categories would clarify the issue. As pointed out by Larrabee and McEntee, ${ }^{32}$ cerebral imaging seems a promising method for the search for such markers in vivo, and some recent studies have investigated anatomical or functional changes in the cerebral images of aged subjects with mild memory or cognitive impairment. ${ }^{17-19} 33$ However, only cross sectional data have been reported so far, and the consistency over time of the cognitive impairment and of the anatomical or functional changes has not been assessed, especially after distinguishing the patients who became demented from those who did not.

The results of the present study show that non-demented elderly patients with mild memory or cognitive impairment have decreased rCBF compared with aged normal controls. Some of the patients with ARCD (five of 18) developed dementia of the Alzheimer type over one to three years, with further decline in memory and rCBF. At initial screening, and before any sign of overt dementia, these patients only differed from the rest of those with ARCD in that they showed a more pronounced temporoparietal asymmetry, the predictive value of which cannot be established from such a small sample. The patients who were not demented after the follow up period still exhibited impaired memory and decreased rCBF compared with controls, but they did not show any further memory or rCBF decline compared with their initial lev- els. At follow up, these non-demented patients with ARCD had higher memory performance than the patients with ARCD who became demented, as well as higher memory and $\mathrm{rCBF}$ than the patients in the probable Alzheimer's disease group.

Thus our results indicate that most of the patients with ARCD cannot be considered as aged normal subjects and yet may not enter a dementing process, at least within the next few years. These findings suggest that ARCD and variants may represent a distinct clinical category, the validation of which, however, will necessitate a follow up period longer than that of the present study.

ARCD AND NORMAL AGING

A decline in memory has been consistently reported in elderly people ${ }^{1-3}$ and is considered as a part of normal aging. However, there is growing evidence that many people aged 80 and over are mentally intact or only very mildly impaired and that they are at low risk for developing dementia. ${ }^{4}$ To establish clinical criteria for distinguishing non-demented aged people with actual memory or cognitive troubles from normal elderly people is not a simple matter, and those proposed for the diagnostic category of AAMI have been criticised ${ }^{35} 36$ or modified. ${ }^{28}$ Because they found a high prevalence of AAMI (38.4\%) in their recent study of a population aged 60 to 78 , Koivisto et al ${ }^{37}$ considered AAMI as a phenomenon of normal aging. However, and as pointed by Larrabee and McEntee, ${ }^{32}$ even when using the contraversial, overinclusive criteria for AAMI, an equivalent proportion of subjects was free of any memory impairment. The criteria we used for selecting our patients with ARCD were different from those for AAMI, especially in that their memory performance was compared to age standardised values, thus narrowing the category. Our careful selection resulted in a group of patients who cannot be considered as aged normal subjects. They differed from controls both in memory performance and in rCBF values, at initial evaluation and at follow up. It could be argued that the initial difference might come from some patients in the ARCD group who, although without any sign of overt dementia at the time of the initial screening, were in the very early phase of a dementing process that will become evident in the next two or three years. This is not the case for our group as the differences in the initial memory performance and $\mathrm{rCBF}$ remained significant after the five patients who became demented during the follow up period had been excluded from the group. The initial decrease in memory and rCBF was confirmed at follow up as the memory performance and rCBF of the non-demented patients with ARCD were still lower than values in the controls.

The consistent decrease in $\mathrm{rCBF}$ in our non-demented patients with ARCD reinforce the view that they may constitute a group distinct from other aged people free of any memory decline. Soininen et al ${ }^{1733}$ have recently documented structural changes in the brain of 
patients with AAMI and of non-demented elderly people with the apolipoprotein $\mathrm{E} \varepsilon 4$ allele. Using quantitative MRI, they found a reduced volume asymmetry between the right and left hippocampus of patients with AAMI compared with aged controls with intact memory. They also found that non-demented elderly subjects carrying the Apo E $\varepsilon 4$ allele, particularly homozygous subjects, had larger left than right hippocampi, whereas the subjects without the $\varepsilon 4$ allele had the reverse. In a first study on the cerebral glucose metabolism of patients with AAMI as measured by PET and ${ }^{18} \mathrm{~F}$-fluorodeoxyglucose, Small et al ${ }^{18}$ failed to find any temporoparietal hypometabolism and only reported lower metabolic ratios in the thalamus and basal ganglia. However, their study lacked a true control group, as they compared patients with AAMI with a familial risk for Alzheimer's disease with patients with AAMI without a familial risk. All their subjects thus presented with some memory impairment. In a second study, Small et al ${ }^{19}$ distinguished patients with AAMI with at least two relatives with Alzheimer's disease, according to their Apo E genotype. They found a significantly lower parietal metabolism and larger left-right parietal asymmetry in the subjects with Apo E $\varepsilon 4$ compared with those without ApoE $\varepsilon 4$. Although their study included a follow up of their subjects, Small et al only reported preliminary data and had not determined if the parietal hypometabolism reflected a very early pathophysiological process in subjects who will develop Alzheimer's disease or if the subjects who will not develop dementia also show such a metabolic pattern. We did not assess the Apo E genotype of our patients with ARCD and only one of them had a family history of Alzheimer's disease. Our results are not directly comparable with those of Small et $a l,{ }^{19}$ but their findings and ours, taken together with those of Soininen et al, ${ }^{1733}$ suggest that structural and functional changes are present in the brain of aged people with memory decline, which are not in the brain of elderly people with intact memory.

\section{ARCD AND ALZHEIMER'S DISEASE}

At one end of the continuum proposed by Brayne and Calloway ${ }^{38}$ is the question of the relation between normal aging and mild memory or cognitive impairment in aged subjects. At the other end is the question of the transition between ARCD and dementia, mainly Alzheimer's disease. An important issue that may be considered in studies such as ours is how many of the patients with ARCD will sooner or later develop dementia. Our study was too short to get a precise idea of that proportion, and it remains uncertain whether there is a subgroup of aged people with a mild but stable memory or cognitive deficits. The available literature offers some support for this view.

The few available longitudinal studies of elderly normal subjects and patients with ARCD generally agree on the stability of the age-related cognitive deficit over time and on the few patients in whom such a decline was prodromal to progressive dementia (for a review, see Caine ${ }^{39}$ ). However, as in our study, the duration of follow up in these studies does not exceed four or five years. The recent studies by Linn $e t a l^{7}$ and Masur et $a l^{6}$ are the first to report a long term follow up (13 and 11 years). Linn $e t a l^{7}$ reported that low scores on the paired associated learning and logical memory tests may be found at least seven years before the diagnosis of probable Alzheimer's disease. The authors thus stressed the long duration of the preclinical phase of the disease. However, Masur et $a l^{6}$ reported that the accuracy of a predictive model based on the neuropsychological performance of aged subjects was highly dependent on the time to diagnosis: the shorter the time, the higher the accuracy of prediction. The studies by Linn $e t a l^{7}$ and Masur $e t a l^{6}$ are surveys of large cohorts of non-demented elderly persons who were not selected on the basis of memory troubles as were our patients with ARCD, and comparisons between the findings require cautious interpretation. However, it seems reasonable to postulate that, given the relative importance of the memory deficit of our patients with ARCD at inclusion compared with controls, most of the subjects actually in the preclinical phase of probable Alzheimer's disease would have develop overt dementia during the follow up period. There was no noticeable decline in memory performance during the follow up in any of our 13 nondemented patients with ARCD. Their average AVMS and DS at the end of the follow up period was even slightly higher than at initial screening. This increase was also found in controls and this may simply reflect a testretest effect.

IS ARCD A CLINICAL AND PATHOLOGICAL ENTITY?

Finally, our results corroborate the findings from the Canadian Study on Health and Aging $^{40}$ regarding the existence of this distinct group. To our knowledge, there is no study reporting the changes in $\mathrm{rCBF}$ or metabolism with time in non-demented patients with memory or cognitive decline. Although decreased compared with controls, the initial rCBF of our patients with ARCD was largely higher than that of the patients with probable Alzheimer's disease, especially in the parietotemporal region. Consequently, the parietotemporal: mean flow ratio did not differ from that of controls and was larger than that of patients with mild to moderate dementia of the Alzheimer type. At initial screening, this ratio did not differentiate the patients with ARCD who will become demented from those who will not. Small et al ${ }^{19}$ found diminished parietal metabolic rates in their relatives at risk for familial Alzheimer's disease and with mild memory complaints compared with values reported in the literature for controls of similar age and higher than a small group of demented patients. The lack of sensitivity of the parietotemporal over mean flow ratio at initial screening may result from the averaging of the left and right regions during a stage of 
the disease when focal, lateralised posterior defects are often found and just lead to an increased asymmetry. Some longitudinal studies have documented the cerebral metabolic changes in early Alzheimer's disease. ${ }^{1041}$ Changes in the pattern (regional ratios) or even in the absolute metabolic rate have been seen as early as after one year of follow up, the deficit in the cortical association areas becoming more pronounced with time. During the follow up period, we found a decrease in absolute flow, and to a lesser degree in the parietotemporal:mean ratio, in our mild to moderately demented patients. Similarly, the five patients with ARCD who became demented showed a clear decrease both in absolute flow and ratio, with values showing a predominant change in the temporoparietal regions. No change was found in the nondemented patients with ARCD, whose $\mathrm{rCBF}$ values remained as stable as those of controls. Our findings thus indicate that the decrease in rCBF in the non-demented patients with ARCD, although consistent over time, is distinct from that in patients with probable Alzheimer's disease: it does not predominate in the temporoparietal association cortices and it does not progress as quickly. Moreover, no temporoparietal asymmetry appeared in our ARCD non-demented patients during the follow up, whereas such an asymmetry seems to be an early sign of rCBF impairment in preclinical Alzheimer's disease. Changes in cerebral function associated with age related decline in memory have been found in nondemented subjects by Grady et al ${ }^{42}$ using PET and a memory activation paradigm. The decrease in $\mathrm{rCBF}$ we found in our nondemented patients with ARCD might reflect the global component of such changes.

Long term longitudinal studies are necessary to establish whether these changes represent a clinical entity. If so, identifying the specific pathological condition corresponding to this clinical entity, in particular with regard to neurotransmitter deficits, would be an important goal for researchers in the field.

This study was supported by grant 998481 from the Institut National de la Santé et de la Recherche Médicale and from the Caisse Nationale d'Assurance Maladie des Travailleurs Salariés. We thank $G$ Viallard for his help in processing the data, and T Pujol, C Blanchard, and N Lavigne for the management of patients and volunteers.

1 Craik FIM. Memory functions in normal aging. In: Yanagihara T, Petersen RC, eds. Memory disorders. research and clinical practice. New York, NY: Dekker, 1991:347-67.

2 Petersen RC, Smith G, Kokmen E, Ivnik RJ, Tangalos EG. Memory function in normal aging. Neurology 1992;42: 396-401.

3 Van Der Linden $M$, Hupet $M$. Le vieillissement cognitif. Paris: PUF, 1994.

4 Petit S, Cardebat D, Agniel A, et al. Apprentissage indicé et diagnostic précoce de la démence de type Alzheimer. L'Année Gérontologique 1994;8:309-20.

5 American Psychiatric Association. Diagnostic and statistical manual of mental disorders. 4th ed. Washington, DC: American Psychiatric Association, 1994.

6 Masur DM, Slivinski M, Lipton RB, Blau AD, Crystal HA. Neuropsychological prediction of dementia and the absence of dementia in healthy elderly persons. Neurology 1994;44:1427-32.

7 Linn RT, Wolf PA, Bachman DL, et al. The preclinical phase of probable Alzheimer's disease. A 13-year prospective study of the Framingham cohort. Arch Neurol 1995;52:485-90.

8 Jacobs DM, Sano M, Dooneief G, Marder K, Bell KL, tion of preclinical Alzheimer's disease. Neurology 1995; 45:957-62.

9 Reed BR, Jagust WJ, Seab JP, Ober BA. Memory and regional cerebral blood flow in mildly symptomatic Alzheimer's disease. Neurology 1989;39:1537-9.

10 Haxby JV, Grady CL, Koss E, et al. Longitudinal study of cerebral metabolic asymmetries and associated neuropsycerebral metabolic asymmetries and associated neuropsy-
chological patterns in early dementia of the Alzheimer chological patterns in early dementir

11 Powers WJ, Perlmutter JS, Videen TO, et al. Blinded clinical evaluation of positron emission tomography for the diagnosis of probable Alzheimer's disease. Neurology 1992;42:765-70.

12 Wolfe N, Reed BR, Eberling JL, Jagust WJ. Temporal lobe perfusion on single photon emission computed tomography predicts the rate of cognitive decline in Alzheimer's disease. Arch Neurol 1995;52:257-62.

13 Kesslak JP, Nalcioglu O, Cotman CW. Quantification of magnetic resonance scans for hippocampal and parahippocampal atrophy in Alzheimer's disease. Neurology 1991;41:51-4.

14 Jack CR, Petersen RC, O'Brien PC, Tangalos EG. MR based hippocampal volumetry in the diagnosis of Alzheimer's disease. Neurology 1992;42:183-8.

15 Petersen RC, Jack CR, Smith G. MRI temporal lobe vol ume measurements and memory function in normal aging. Neurology 1991;41 (suppl 1):341

16 Golomb J, Kluger A, de Leon MJ, et al. Hippocampal formation size in normal human aging: a correlate of delayed secondary memory performance. Learning and Memory 1994;1:45-54

17 Soininen HS, Partanen KC, Pitkänen A, et al. Volumetric MRI analysis of the amygdala and the hippocampus in subjects with age-associated memory impairment: correlation to visual and verbal memory. Neurology 1994;44: 1660-8.

18 Small GW, Okonek A, Mandelkern MA, et al. Age-associated memory loss: initial neuropsychological and cerebral metabolic findings of a longitudinal study. Int Psychogeriatr 1994;6:21-43.

19 Small GW, Mazziotta JC, Collins MT, et al. Apolipoprotein E type 4 allele and cerebral glucose metabolism in relatives at risk for familial Alzheimer's disease. $7 A M A$ 1995;273:942-7.

20 Derouesné C, Dealberto MJ, Boyer P, et al. Empirical evaluation of the cognitive difficulties scale for assessment of memory complaints in general practice: a study of 1628 cognitively normal subjects aged 45-75 years. International fournal of Geriatric Psychiatry 1993;8. 599-607.

21 McNair DM, Kahn RJ. Self-assessment of cognitive deficits. In: Crook T, Ferris S, Bartus R, eds. Assessment in geriatric psychopharmacology. New Canaan: Mark Powley Associates, 1984:137-43.

22 Folstein MF, Folstein SE, McHugh PR. Mini mental state: a practical method for grading the cognitive state of a practical method for grading the cognitive state of
patients for the clinician. $\mathscr{F}$ Psychiatr Res 1975;12:189-98.

23 Wechsler D. A standardized memory scale for clinical use. Psychol 1945;19:87-95.

24 Hamilton $M$. Development of a rating scale for primary depressive illness. British fournal of Social and Clinical Psychology 1967;6:278-96.

25 Levy R. Aging-associated cognitive decline. Working party of the International Psychogeriatric Association in collaboration with the World Health Organization. Int Psychogeriatr 1994;6:63-8.

26 American Psychiatric Association. Diagnostic and statistical manual of mental disorders. Revised 3rd ed. Washington, DC: American Psychiatric Association, 1987

27 Crook T, Bartus RT, Ferris SH, Whitehouse P, Cohen GD, Gershon S. Age-associated memory impairment: proposed diagnostic criteria and measures of clinical proposed diagnostic criteria and measures of clinical change-report of a National Institute of Mental

28 Blackford RC, LaRue A. Criteria for age-associated memory impairment: proposed improvements from the field. Dev Neuropsychol 1989;5:295-306.

29 World Health Organization. The ICD-10 classification of mental and behavioural disorders: diagnostic criteria for research. Geneva: World Health Organization, 1993.

30 Celsis P, Goldman T, Henriksen L, Lassen NA. A method for calculating regional cerebral blood flow from emission computed tomography of inert gas concentrations. Comput Assist Tomogr 1981;5:641-5.

31 Talairach J, Tournoux P. Co-planar stereotaxic atlas of the human brain. Stuttgart, Germany: Georg Thieme Verlag, 1988.

32 Larabee GJ, McEntee WJ. Age-associated memory impairment: sorting out the controversies. Neurology 1995;45 $611-4$

33 Soininen H, Partanen K, Pitkänen A, et al. Decreased hippocampal volume asymmetry on MRIs in non demented elderly subjects carrying the apolipoprotein E e4 allele. Neurology 1995;45:391-2

34 Katzman R, Aronson M, Fuld P, et al. Development of dementing illnesses in an 80 year old volunteer cohort. Ann Neurol 1989;25:317-24.

35 Smith G, Ivnik RJ, Petersen RC, Malec JF, Kokmen E, Tangalos E. Age-associated memory impairment diag noses: problems of reliability and concerns for terminology. Psychol Aging 1991;6:551-8.

36 O'Brien JT, Levy R. Age associated memory impairment. Too broad an entity to justify drug treatment yet. $B M \mathcal{F}$
1992;304:5-6. 
37 Koivisto K, Reinikainen KJ, Hänninen T, et al. Prevalence of age-associated memory impairment in a randomly selected population from eastern Finland. Neurology 1995;45:741-7.

38 Brayne C, Calloway P. Normal ageing, impaired cognitive function, and senile dementia of the Alzheimer's type: continuum? Lancet $1988 ; i \cdot 1265-7$.

39 Caine ED. Should aging-associated cognitive decline be Neuropsychiatry Clin 1993;5:1-5.
40 Ebly EM, Hogan DB, Parhad IM. Cognitive impairment in the nondemented elderly. Results from the Can Study of Health and Aging. Arch Neurol 1995;52:612-9.

41 Smith GS, de Leon MJ, George AE, et al. Topography of cross-sectional and longitudinal glucose metabolic deficits in Alzheimer's disease. Arch Neurol 1992;49. 1142-50.

42 Grady CL, McIntosh AR, Horwitz B, et al. Age-related reductions in human recognition memory due to impaired encoding. Science 1995;269:218-21. 